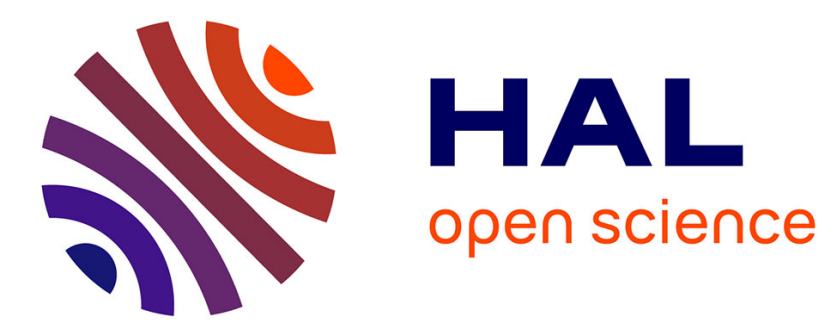

\title{
Les Northmanni en Francie occidentale au IXe siècle: le chant de Louis
}

\author{
Jens Schneider
}

\section{To cite this version:}

Jens Schneider. Les Northmanni en Francie occidentale au IXe siècle: le chant de Louis. Annales de Normandie, 2003, 53, pp.291-315. hal-01093595

\section{HAL Id: hal-01093595 \\ https://hal.science/hal-01093595}

Submitted on 28 Jun 2021

HAL is a multi-disciplinary open access archive for the deposit and dissemination of scientific research documents, whether they are published or not. The documents may come from teaching and research institutions in France or abroad, or from public or private research centers.
L'archive ouverte pluridisciplinaire HAL, est destinée au dépôt et à la diffusion de documents scientifiques de niveau recherche, publiés ou non, émanant des établissements d'enseignement et de recherche français ou étrangers, des laboratoires publics ou privés. 


\section{Les Northmanni en Francie occidentale au IXe siècle. Le chant de} Louis

Jens Schneider

Citer ce document / Cite this document :

Schneider Jens. Les Northmanni en Francie occidentale au IXe siècle. Le chant de Louis. In: Annales de Normandie, $53^{e}$ année, $n^{\circ} 4$, 2003. pp. 291-315;

doi : https://doi.org/10.3406/annor.2003.1453

https://www.persee.fr/doc/annor_0003-4134_2003_num_53_4_1453

Fichier pdf généré le 19/04/2018 


\section{LES NORTHMANNI EN FRANCIE OCCIDENTALE AU IX ${ }^{\text {e }}$ SIÈCLE LE CHANT DE LOUIS}

Entre Abbeville et Eu, dans le Vimeu, non loin de la frontière de la Normandie, se trouve le lieu-dit Saucourt ${ }^{2}$. C'est là, à Sathulcurtis, probablement une sorte de villa rustica à l'époque, que se produisit l'une des rares victoires franques sur les Vikings. A part les traditions historiographiques des annales et des chroniques, il nous est parvenu un texte littéraire qui nous fournit des informations sur cet événement, la bataille dite de Saucourt. Le "Chant de Louis », Ludwigslied en allemand, a été nommé ainsi parce qu'il décrit en langue francique la victoire du jeune roi Louis III, petit-fils de Charles le Chauve, sur un groupe de Vikings au mois d'août $881^{3}$. Pour vous familiariser avec le Chant de Louis III, je vais procéder en trois temps : dans un premier temps, je présenterai le texte dans son contexte, puis je discuterai le problème des invasions scandinaves pour parvenir, dans un troisième temps, à une analyse plus proche de la source.

Notre protagoniste est Louis III, fils de Louis dit Balbus, le Bègue, fils de Charles le Chauve, qui était, on le sait, petit-fils de Charlemagne. Charles le Chauve, le roi de Francie occidentale depuis le fameux traité de Verdun de 843 , qui devint empereur en 875 , est mort en 877 . Son héritier et successeur était son fils mal aimé, Louis, qui avait fait une alliance contre la volonté de son père avec Ansgarde, fille du comte bourguignon Harduin ${ }^{4}$. De ce premier mariage, il avait deux fils, Louis et Carloman; en 878 il repoussa leur mère pour épouser la fille du comte Adalard. Quand il mourut, en 879 , sa deuxième femme était enceinte d'un fils, le futur Charles le Simple. Louis le Bègue avait prévu comme successeur son fils ainé, Louis III. Or ses dernières volontés ne furent pas respectées par tous les grands du royaume. Mettant

1 Le présent article est la publication d'une intervention tenue à l'Université de Caen Basse-Normandie le 15 mai 2002. Je remercie vivement François Neveux pour l'invitation, pour la lecture critique et pour de nombreuses corrections dans mon texte.

2 Commune de Nibas, canton de Friville-Escarbotin, arrondissement d'Abbeville, département de la Somme.

3 Je cite ici ma propre édition du Rithmus teutonicus dont la publication avec traduction française est prévue. Des nombreuses éditions je signale celle du Althochdeutsches Lesebuch, éd. W. BraunE et E. A. EbBinghaus, Tübingen 1979, p. 136-138. Sur l'événement voir infra n. 28.

4 Pierre RICHÉ, Les Carolingiens. Une famille qui fit l'Europe, Paris 1983, p. 205. Cf. Régine LE JAN, Famille et pouvoir dans le monde franc (VIr'- $X^{e}$ siècle). Essai d'anthropologie sociale, Paris 1995, p. 267-68. 
en cause la légitimité du premier mariage de Louis le Bègue, un parti proposait même le trône au roi de Francie orientale, Louis le Jeune, fils de Louis le Germanique. Après ces querelles de succession, les grands tombèrent finalement d'accord pour diviser le regnum occidental en deux - tradition franque - et pour faire couronner par conséquent les deux frères du premier mariage de Louis le Bègue. La partie septentrionale revenait à Louis III, qui n'avait 16 ans au maximum ; elle comprenait Paris et surtout Compiègne, le palais préféré de Charles le Chauve d'après le modèle d'Aixla-Chapelle, et donc les anciennes Neustrie et Francie. La partie méridionale, comprenant l'Aquitaine et la Bourgogne (le futur duché), fut donnée à son frère cadet, Carloman ${ }^{5}$.

Louis III ne survécut pas longtemps à son père. Quand il mourut en 882 , d'un accident de cheval, le royaume occidental fut réunifié sous l'autorité de Carloman qui mourut à son tour en 884. D'après les Annales de Saint-Vaast l'accident mortel de Louis se déroula ainsi :

"Le roi, car il était jeune, pourchassait une jeune fille, en plaisantant : monté á cheval, il la suivit jusqu'à la demeure de ses parents, où elle se réfugiait, mais au moment de franchir la porte il se heurta les épaules et la poitrine. A la suite de ces blessures, il mourut le 5 août à Saint-Denis, où il s'était fait porter, à la grande douleur des Francs "\%.

Rétrospectivement, les aléas de la succession de l'empereur Charles le Chauve donnent l'image d'une série de malheurs La situation fut certainement ressentie de cette façon au tournant des années $884-885$, lorsque la mort du dernier héritier capable de gouverner laissa le regnum occidental au fils posthume de Louis le Bègue, âgé de 5 ans. De plus, vers la même époque eurent lieu les bella Parisiace urbis que nous raconte Abbon de Saint-Germain7. Après les décès successifs des deux derniers rois qui paraissaient garantir une continuité dans les deux Francies, orientale et occidentale (Louis le Germanique en 876 , son frère Charles le Chauve l'année suivante), les crises de succession ainsi que les raids vikings s'aggravant depuis 879 ont facilement été compris comme une punition divine. Quand cependant en

5 Sur les problèmes de succession et le nouveau partage en deux regna voir Annales de Saint-Bertin, éd. F. Grat et al. (Société de l'Histoire de France), Paris 1964 [cit. Ann.Bert.] ; RICHE, Carolingiens, p. 205-209; Karl Ferdinand WI:RNI:R, "Gauzlin von Saint-Denis und dic westfränkische Reichsteilung von Amiens (März 880). Ein Beitrag zur Vorgeschichte von Odos Königtum », in: Deutsches Archiv 35 (1979), p. 395-462. Voir aussi Brigitte KASTEN, Königssöhne und Königsherrschaft. Untersuchungen zur Teilhabe am Reich in der Merowinger- und Karolingerzeit, Hannover 1997, p. 480-489, qui souligne le rôle de Boson et sa femme Ermengarde, tante de Louis le Bègue.

6 Annales Vedastini (MGH SS rer. Germ. 12), a. 882, p. 52 : Sed quia izvenis erat, quandam puellam, filiam cuiusdam Germundi, insecutus est : illa in domo paterno fugiens, rex equo sedens iocando eam insecutus scapulas superliminare et pectus sella equi attrivit eumque valide confregit. Unde egrotare coepit et delatus apud Sanctum Dionisium Nonis Augusti defunctus maximum dolorem Francis reliquit (toutes traductions J. S.).

7 Abbon, Le Siège de Paris par les Normands. Poème du IX $X^{\prime}$ siècle (Les Classiques..., 20), Paris 1964. 
881, peu après la défaite de son chancelier Gauzlin, pourtant expérimenté, Louis III fit preuve d'un dynamisme efficace, il fut regardé comme représentant d'une nouvelle génération de rois carolingiens. C'est Notker de SaintGall qui a utilisé l'expression de spes Europae à propos de Louis III et de son frère, un espoir pour l'Europe qui paraissait contredire les peurs du déclin de la royauté carolingienne ${ }^{8}$. Jusqu'à la mort surprenante de ce jeune roi prometteur, douze mois plus tard, l'ambiance dans le royaume occidental fut peut-être moins sombre.

Sous le titre Rithmus teutonicus de piae memoriae Hluduico rege filio Hluduici aeque regis on trouvera notre texte dans le manuscrit 150 de la Bibliothèque municipale de Valenciennes, qui conserve les archives de l'ancienne abbaye Saint-Amand (fol. $\left.141^{\mathrm{v}}-143^{\mathrm{r}}\right)^{9}$. Il s'agit d'un codex du $\mathrm{IX}^{\mathrm{C}}$ siècle qui a été relié au $X \mathrm{~V}^{\mathrm{C}}$ siècle en peau de bison non apprêtée, ce qui lui a valu le surnom de liber pilosus ${ }^{10}$. Quand a-t-on inscrit le «Chant de Louis » dans ce « livre pelu »? Le chant glorifie la victoire du jeune roi encore vivant sur les Northmanni, mais la copie dans le manuscrit fut faite de piae memoriae. Cela nous donne un cadre assez fiable pour dater l'œuvre et sa mise par écrit : Le Rithmus fut sans doute composé entre la victoire de Saucourt, le 3 août 881 et la mort de Louis le 5 août 882 ; mais ce n'est qu'après qu'il fut copié dans notre manuscrit. Le codex fit longtemps partie de la bibliothèque de l'abbaye de Saint-Amand, aujourd'hui ville de SaintAmand-les-Eaux, située entre Valenciennes et Tournai" ${ }^{\prime \prime}$. Le monastère a été fondé au $\mathrm{VII}^{\mathrm{e}}$ siècle par Amandus, qui a su obtenir du roi Dagobert $(\dagger 639)$ l'immunité pour sa fondation préférée. Le monastère fut d'abord nommé Elno, d'après le nom d'un petit confluent de la Scarpe qui représentait la frontière entre les diocèses de Cambrai et d'Arras. Prenant ensuite le nom de son fondateur, l'abbaye s'appela Saint-Amand-sur-l'Elnon. Elle semble avoir fait partie des «principaux foyers intellectuels de l'Occident» de l'époque de Charles le Chauve jusqu'au $\mathrm{X}^{\mathrm{e}}$ siècle ${ }^{12}$.

8 Notker Balbulus, Continuatio Erchanberti (MGH SS 2), p. 330 : ... duobus filiis superstitibus, Ludovico videlicet et Carlomanno, qui nunc in primaeva aetate spes adolescunt et iam florescunt Europae.

9 Sur le manuscrit et son histoire Bernhard BISCIIFF, "Paläographische Fragen deutscher Denkmäler der Karolingerzeit », in : id., Mittelalterliche Studien. Ausgewählte Aufsätze zur Schriftkunde und Literaturgeschichte, Stuttgart 1981, t. 3, p. 73-111, p. 108-109; Elnonensia. Monuments des langues romane et tudesque dans le I $X^{t}$ siècle [...] publiés par HOFMANN DE FALLERSLEBEN, avec une traduction et des remarques par J. F. WILLEMS, Gand 1837, p. 3-4 ; Françoise SIMERAY, "La Découverte de la Cantilène de sainte Eulalie », in Marie-Pierre DION (dir.), La Cantilène de sainte Eulalie. Actes du colloque de Valenciennes 21 mars 1989, Lille et Valenciennes 1990 [cit. Eulalie 1990], p. 53-60.

10 Simeray, Découverte, p. 54 (photographie).

11 Chef-lieu de canton, arrondissement de Valenciennes, département du Nord. Sur Saint-Amand voir Edouard DE MOREAU, Saint Amand. Apôtre de la Belgique et du Nord de la France, Louvain 1927, p. 115 : «II l'aima, comme plus tard Boniface aimera Fulda ». Important : Marie-Pierre Dron (dir.), La Cantilène de sainte Eulalie, op. cit. : cf. la contribution du chanoine Henri PI.ATHLLL, " L'abbaye de St-Amand au IX ${ }^{c}$ siècle », p. 18-34.

12 Marie-Pierre Dion, « Le Scriptorium et la bibliothèque de l'abbaye de St-Amand au IX $\mathrm{X}^{\mathrm{e}}$ siècle ", in : Eulalie 1990, p. 35-52, p. 35. 
Ce n'est toutefois pas dans ce scriptorium que le "Chant de Louis " a été copié, mais dans un autre monastère en Basse-Lotharingie comme l'a constaté Bernhard Bischoff ${ }^{13}$. Au XII ${ }^{\mathrm{e}}$ siècle cependant, le codex en question se trouve à Saint-Amand, comme le montre l'ex-libris du Liber sancti Amandi, au dernier feuillet, ainsi qu'une entrée du catalogue de cette époque ${ }^{14}$. On a supposé que le volume avait été donné à Saint-Amand lors de la reconstitution de la bibliothèque après les années d'invasion ${ }^{15}$. Louis III a très probablement battu à Saucourt des membres de la même "grande armée " scandinave qui avaient infligé une défaite à Gauzlin. Sans doute rendaient-ils visite aux moine installés sur l'Elnon. Ils ont brûlé ce qu'ils n'emmenaient pas des trésors de l'abbaye, manuscrits et autres. Ne fut sauvé que ce qui avait été mis à l'abri à Saint-Germain-des-Prés, autre monastère de l'abbé laïc Gauzlin. Le codex en question a probablement été fait pour une copie des sermons de Grégoire de Nazianze ou bien de Grégoire le Grand ; peu après on a ajouté trois poèmes latins, dont l'un sur sainte Eulalie, puis la cantilène de sainte Eulalie en ancien français et, comme avant-dernière entrée, continuant sur deux feuillets supplémentaires (fol. 142 et 143), le Rithmus teutonicus ${ }^{16}$. On a souligné le caractère trilingue de ce manuscrit. L'abbaye de Saint-Amand possédait aussi un autre codex du début du $\mathrm{X}^{\mathrm{e}}$ siècle contenant "le brouillon d'un sermon bilingue sur Jonas $~^{17}$ : elle apparaît donc comme un foyer extraordinaire de plurilinguisme. "Les textes de St-Amand témoignent en effet d'une interpénétration linguistique et d'une communauté culturelle qu'on ne peut laisser dans l'ombre sans fausser bien des perspectives " comme l'a constaté Maurice Delbouille ${ }^{18}$. On s'est souvent demandé pourquoi un poème vernaculaire qui glorifie le roi Louis en francique rhénan traite un événement de la partie occidentale de l'empire franc. On répondra que pratiquement partout dans cet empire il y avait des nobles qui étaient plus ou moins bilingues et parlaient la langue

13 BISCHOFF, Paläographische Fragen, p. 109 : « wohl kaum mehr bestimmbares Zentrum des linksrheinischen, niederlothringischen Gebietes ».

14 SIMERAY, Découverte, p. 55.

15 Recueil des actes de Charles III le Simple, éd. F. LOT et Ph. LAuER (Chartes et diplomes...), Paris 1939, no. 18, p. 29-33 : Reims 899 mars 17. Platelle, L'abbaye, p. 2731 : Simeray, Découverte, p. 54-55. Sur les Vikings à Saint-Amand voir les Annales Sancti Martini Tornacensis (MGH SS 15.2), a. 881 et les Annales Elnonenses maiores (MGH SS 5), a. 884 .

16 DION, Scriptorium, p. 48-49 ; Elias vON STEINMEYER, Die kleineren althochdeutschen Sprachdenkmäler, Berlin 1916, p. 87. Sur la cantilène de sainte Eulalie voir Guy DE POERCK, "Les plus anciens textes de la langue française comme témoins de l'époque », in: Revue de linguistique romane 27 (1963), p. 1-34 ; Gerold HILTY, "La séquence de Sainte Eulalie et les origines de la langue littéraire française ", in : Vox Romanica 27 (1968), p. 4-18 ; Eulalie 1990 (n. 10).

17 Valenciennes : B. M., ms. 521. Dion, Scriptorium, p. 48.

18 Maurice Delboullee, "A propos des deux séquences de l'Eulalie et du Ludwigslied ", in : Interlinguistica, Mél. M. WANDRUSZKA, Tübingen 1971, p. 26-38, p. 38 ; cf. Ruth HARVEY, "The Provenance of the Old High German Ludwigslied », in : Medium AEvum 14 (1945), p. 1-20, p. 18-19 ; Albert Louis RossI, Vernacular Authority in the Late Ninth Century: Bilingual Juxtaposition in MS 150, Valenciennes, Ann Arbor 1987 (Microfiche), p. $571-72$. 
francique, qu'elle soit leur langue maternelle ou non. Et surtout, dans les anciennes terres centrales des Francs comme la Neustrie et l'Austrasie, la plupart des grands comprenaient le francique ${ }^{19}$. Il y avait donc un public pour le « Chant de Louis ». Celui-ci a été ajouté à la fin d'un codex, au cours dernières années du $\mathrm{IX}^{\mathrm{e}}$ siècle, dans une caroline bien mesurée, quelque part non loin de Saint-Amand. En même temps et par la même main sûre et légère fut insérée la cantilène de sainte Eulalie, le plus ancien témoignage littéraire de l'ancien français.

C'est encore à Saint-Amand que le savant bénédictin Jean Mabillon tomba sur notre manuscrit, en 1672 ; il ne prêta pas grande attention à la cantilène en ancien français, mais fit une copie rapide du Rithmus, qu'il montra à son ami Johannes Schilter à Strasbourg. Schilter n'était point satisfait de l'état du texte et chercha à le faire collationner. Cependant, il fut impossible de retrouver le manuscrit que Mabillon avait eu entre les mains; après un tremblement de terre en 1692 la bibliothèque de Saint-Amand semble avoir été désorganisée. Schilter se décida pourtant à imprimer le «Chant de Louis » pour la première fois, en 1696, malgré son caractère imprécis que ${ }^{20}$. Il y eut une deuxième édition en 1728 , et ensuite, on admit que l'original du Rithmus avait été perdu. C'est là que commence la partie aventureuse de l'histoire du poème.

Un jeune chercheur allemand se mit en tête de retrouver cet introuvable manuscrit. August Heinrich Hoffmann, qui se faisait appeler von Fallersleben d'après le lieu de sa naissance, avait, en spécialiste des anciennes langues germaniques, publié en 1830 unc vcrsion du Rithmus sur la base de l'édition de Schilter. ${ }^{21} \mathrm{C}$ 'était un bibliomane qui adorait exploiter des archives pour trouver des trésors littéraires et qui s'y vouait avec un certain succès. Hoffmann fut bibliothécaire à l'université de Bonn, puis professeur à celle de Breslau, toutes deux fondées peu de temps auparavant par le roi de Prusse, Friedrich Wilhelm. Il tomba en disgrâce pour des raisons politiques et termina ses jours comme bibliothécaire du prince de Ratibor et duc de Corvey, sur la Weser, en Westphalie. Or, pendant un voyage qui le menait dans plusieurs dépôts d'archives, il découvrit en effet ce manuscrit à Valen-

19 Wolfgang HaUBRICHS, Die Anfänge: Versuche volkssprachiger Schriftlichkeit im frühen Mittelalter (Geschichte der deutschen Literatur..., I.1), Tübingen 1995, p. 144. Pour la " coexistance des trois idiomes" (DELboullle, deux séquences, p. 27) voir Rosamond MCKITTERICK, The Carolingians and the written word, Cambridge 1989 ; $\mathrm{cf}$. la réaction de Ernst HEL. .GARDT, «Zur Mehrsprachigkeit im Karolingerreich », in : Beiträge zur Geschichte der deutschen Sprache und Literatur 118 (1996), p. 1-48.

20 EIINIKION. Rhythmo teutonico Ludovico regi acclamatum, cum Nortmannos an. DCCCLXXXIII vicisset. ... Interpretatione latina \& commentatione historica illustravit Johannes SCHILTER, Strasbourg 1696. Sur le désordre de la bibliothèque, il nous est conservé le texte d'une lettre de D. R. DE Los qui fut envoyé par Mabillon pour une nouvelle collation du Rithmus : ibid. p. 8.

21 August Heinrich HofFMAnN, Fundgruben für Geschichte deutscher Sprache und Literatur, $1^{\text {ire }}$ partie, Breslau 1830 , p. 4-9. Ce prototype du savant romantique composa plus tard le texte de l'hymne national allemand. 
ciennes, dans un fonds se trouvant apparemment dans un désordre total, depuis le transfert des archives de Saint-Amand, à l'époque de la Révolution. Aussitôt il prépara une édition du texte avec traduction latine et commentaire, en collaboration avec son ami J. F. Willems à Gand, où le volume parut en 1837 sous le titre d'Elnonensia ${ }^{22}$. Depuis, ce texte est devenu un classique de la littérature allemande du Moyen Age. Jacob Grimm a forgé le nom de «Ludwigslied »; Johann Gottfried Herder et maints successeurs l'ont traduit en allemand moderne; le texte est présenté dans tous les recueils de classiques en vieil allemand ${ }^{23}$. Mais c'est également, comme j'espère pouvoir le montrer, une source intéressante pour l'historien, même si celui-ci n'a plus l'esprit romantique du XIX ${ }^{\mathrm{e}}$ siècle.

Le «Ludwigslied » raconte d'abord en 59 vers comment Dieu fait venir les Northmanni chez les Francs, puis comment il envoie un sauveur, qui se réjouit du secours divin. L'emploi du terme Viking ou Normand est synonyme. Le Northmannus est l'homme du Nord, le mot Viking est la forme moderne d'un terme vieil anglais du VIII ${ }^{\mathrm{e}}$ siècle, wicing, qui semble signifier les "spécialistes du combat " $^{24}$. Le terme "Viking" permet de distinguer plus clairement les envahisseurs scandinaves des futurs habitants de la Normandie. Pourtant, le mot ne figure pas dans les sources continentales, où il est question de Nortmanni, Dani et pyratae. On s'est demandé si la peur des pyratae danois avait été instrumentalisée pour des intentions politiques très concrètes. Or, nous ne parlons pas ici d'un texte historiographique, mais d'un monument poétique, en vieux francique.

C'est également la forme littéraire du chant qui a été discutée. La question mérite d'être posée, même si nous ne pouvons pas entrer ici dans les détails philologiques. Car il ne s'agit pas d'un ancien texte de tradition germanique, transformé par un clerc, ou d'un supposé chant héroïque, « Heldenlied ", faisant partie des barbara et antiquissima carmina de Charle-

22 Supra n. 8. Sur la re-découverte du manuscrit ibid. et Paul LiFRANCQ, Rhythmus Teutonicus ou Ludwigslied? De la découverte de Mabillon (Saint-Amand, 1672; à celle d'lloffmann von Fallersleben (Valenciennes, 1837), Paris 1945. L'année 1791 pour le transfert dans les archives de la sous-préfecture à Valenciennes a été suggérée par STIEINMI:YER, Sprachdenkmäler, p. 87.

23 Jacob GRIMM, "Über das Ludwigslied », in : Germania 1 (1886), p. 233-235. Johann Gottfried HERDER, Volkslieder, t. 2, Leipzig 1779, p. 227-232.

24 René LEPELLEY, "Considérations étymologiques sur le mot Viking ", in : Annales de Normandie 52 (2002), p. 67-72. L'argument de M. Lepelley, qui voit un composé des trois éléments, courants dans les langues germaniques du VII'- $X^{\mathbb{C}}$ s., wîg (combat), kin (espèce ) et le suffixe ing signifiant l'appartenance à un groupe de personnes, est convaincant : ${ }^{*}$ wigkining > va. uuicing[sceadan] ( $\mathrm{VII}^{\mathrm{e}} \mathrm{s}$.) $>$ va. wigcing/wicing (VIII"s.) > vn. vikingr. On devra dès lors corriger d'anciennes étymologies tellc quc < celui qui habite ou navigue dans les baies > ou < celui qui entreprend une expédition ?. Sur les questions étymologiques des noms d'hommes, bateaux, chevaux, armes etc. voir Lucien MusS\$:T, Les Invasions, t. 2 : Le second assaut contre l'Europe chrétienne (VII'-XI' siècles), Paris 1965, p. 107-115; Horst ZFTTEL, Das Bild der Normannen und der Normanneneinfälle in westfränkischen, ostfränkischen und angelsächsischen Quellen des 8. bis 12. Jahrhunderts, München 1977, p. 33-57, à lire avec le compte rendu de Wilfried HARTMANN in Deutsches Archiv 34 (1978), p. 281 ; Jean Rinaud, Les Vikings et la Normandie, Rennes 1989, p. 13-31. 
magne mentionnées par Eginhard ${ }^{25}$. Ce n'est pas non plus une pièce de propagande, ecclésiastique ou autre, destinée à défendre un modèle de royauté ou à implorer de l'aide contre un parti opposé, dans les querelles du regnum. Tout cela a été proposé ${ }^{26}$. Le Rithmus est, en revanche, comme on a pu le démontrer, une pièce poétique contenant à la fois des éléments traditionnels et des éléments modernes. Faisant l'éloge d'un roi victorieux, qui plus est plus en langue barbare, avec l'ancienne graphie Hluduig, l'auteur manifeste bien un côté conservateur. Mais c'est en même temps un homme très habile, qui mélange des éléments de la poésie latine à la structure poétique prédominante des langues germaniques, qui est également celle du vieil anglais, du vieil irlandais et, évidemment, des autres monuments du vieil allemand. I1 s'agit d'un long vers coupé en deux par une césure. L'auteur utilise une technique novatrice en combinant ce vers avec la rime ${ }^{27}$ mais, en même temps, il essaie d'imiter l'ancien procédé germanique de l'allitération. Il compose ainsi un panegyricus qui combine un esprit novateur avec une certaine nostalgie pour l'époque carolingienne. Tout ceci ne veut pas dire, bien entendu, que ce chant ne comporte pas de message. Selon Jean Carles, « il s'agit de montrer le triomphe de la foi sur le paganisme ... Histoire et religion s'impliquent et se complètent $»^{28}$. La fonction première du Rithmus n'était pas d'exercer une influence d'ordre politique, de dénoncer un groupe ou un modèle idéologique, mais de louer le roi chrétien modèle. En ce qui concerne la copie qui nous est parvenue, il s'agissait aussi de célébrer sa mémoire.

Regardons de plus près. On a suggéré le cadre structurel suivant. Le poème s'ouvre par les deux premiers vers, qui introduisent les protagonistes et présentent une histoire de salut. Suivent deux parties présentant d'un côté

25 Eginhard, Vie de Charlemagne, éd. L. HALPHEN (Les Classiques...), Paris 1981, c. 29, p. 82. Cf. Klaus MAT7EI, "Karl der Große und die lingua theodisca », in : Rheinische Vierteljahrsblätter 34 (1970), p. 172-189; HaUBRICHS, Anfänge, p. 111-114.

26 Quant au chant héroïque voir la discussion chez Heinrich BFCK, "Zur literaturgeschichtlichen Stellung des althochdeutschen Ludwigsliedes und einiger verwandter Zeitgedichte", in: Zeitschrift für deutsches Altertum 103 (1974), p. 37-51. Pour une polémique dans le cadre de la querelle de succession : Trude EHLERT, "Literatur und Wirklichkeit Exegese und Politik", in : Saeculum 32 (1981), p. 31-42 ; Raimund KEMPER, "Das Ludwigslied im Kontext zeitgenössischer Rechtsvorgänge », in : Deutsche Vierteljahresschrift für Literaturwissenschaft 56 (1982), p. 161-173 ; Holger HOMANN, "Das Ludwigslied Dichtung im Dienste der Politik ? », in : Traditions and Transitions, Mél. H. JANTZ, München 1972, p. 17-28; Klaus J. MATTHIFIER, " Historisches und Figuratives im althochdeutschen Ludwigslied", in : Philologische Untersuchungen, Mél. E. STUTZ, Wien 1984, p. 270-288; Robert MÜLLER, « Das Ludwigslied - cine Dichtung im Dienste monarchischer Propaganda für den Kampf gegen die Normannen ? ", in : P. K. STEIN (dir.), Sprache-Text-Geschichte, Göppingen 1980, p. 441-477; David N. YfandLE, «The Ludwigslied : King, Church, and Context ", in : J. L. FlOOD, D. N. YE.ANDI.E (dir.), 'mit regulu bithuungan'. Neue Arbeiten zur althoch-deutschen Poesie und Sprache, Göppingen 1989, p. 18-79.

27 On ne connaît cette technique que chez Otfrid de Wissembourg qui créa une version poétique des évangiles en langue francique. HaRvey, Provenance p. 7-11 ; Haubrichs, Anfänge, p. 292-312 ; Jens SCHNEIDER, "Historische Anmerkungen zu Otfrid ", in : De consolatione philologiae, Mél. E. S. FIRCHOW, Göppingen 2000, t. 2, p. 342-358.

28 Jean CARLES, "Le Ludwigslied et la victoire de Louis III sur les Normands à Saucourt-en-Vimeu (881) ", in : La Chanson de geste et le mythe carolingien, Mél. R. Lovis, Saint-Pierre-sous-Vézelay 1982, t. 1, p. 101-109; cf. DELBOUILLE, deux séquences, p. 34. 
Louis (v. 3-8) et de l'autre côté le peuple franc, responsable de la dislocation du regnum en raison de ses péchés (v. 11-18). L'auteur du Rithmus ne met pas l'accent sur les antécédents carolingiens du roi, mais sur des prédécesseurs bibliques. Louis n'est pas (encore) caractérisé comme un héros, mais par l'affirmation des vertus chrétiennes du souverain. Ces deux thèmes sont étroitement liés par la fonction des Vikings agissant comme instruments divins : leur rôle est de punir les Francs et d'éprouver le souverain selon le modèle biblique (v. 9-12).

"So thaz uuarth al gendiot. Koron uuolda sin god.

Ob her arbeidi. So iung tholon mahti.

Lietz her heidine man. Obar seo lidan.

Thiot urankono. Manon sundiono".

"Lorsque cela fut terminé Dieu voulut l'éprouver, s'il pouvait, tout jeune qu'il fut, effectuer de pénibles travaux. Aux hommes païens, il fit traverser la mer, exhorter le peuple des Francs, à cause de leurs péchés ».

Les païens préparent la scène pour l'entrée du sauveur en créant la situation dans laquelle il se révélera. C'est en l'absence de ce sauveur que se répend la détresse. Ainsi, la crise est présentée comme le résultat de l'absence du roi. Cet état de fait se répétera lors de la bataille à venir. La partie centrale du chant est composée sous la forme d'un dialogue, ou plutôt d'un discours, illustrant la mission divine (v. 21-28), ainsi que le rapport du roi avec ses combattants (v. 29-41). Après la description de la bataille (v. 42-56), le cadre poétique du chant est fermé par trois vers qui, en conclusion, forment une suite de remerciements et de vœux de salut. Ces derniers visent aussi bien le présent avec les laudes royales (v. 57-58) ${ }^{29}$ que le futur, en appelant sur le roi la grâce et la faveur divines.

Le contexte historique du "Chant de Louis ", c'est d'abord la lutte entre les Francs et les Vikings. Suivant les indices biographiques qui sont donnés au début de la chanson, on a assez tôt identifié le roi du poème comme étant Louis III, et la bataille avec ce qui s'est passé à Saucourt le 3 août 881 , événement bien documenté dans les sources. C'est encore à Jacob Grimm que remonte cette identification historique, bien que ce fût Ernst Dümmler qui la démontra précisément ${ }^{30}$.

L'image des Vikings qui, dès la fin du VIII ${ }^{\mathrm{c}}$ siècle, apparurent aux habitants des littoraux européens avec leurs navires, et commencèrent à remonter les fleuves, doit faire l'objet d'une évaluation critique des sources. Il est incontestable que ces troupes belliqueuses et pillardes de Nortmanni, que nous décrivent les historiographes contemporains, ont bel et bien existé.

29 Voir infra.

30 GRIMM, Ludwigslied ; Ernst DüMMLER, Geschichte des ostfränkische Reiches, t. 3, Leipzig 1888, p. 152-156. Rapport des sources: Annales Vedastini a. 881 ; Annales Fuldenses (MGH SS rer. Germ. 7) [cit. Ann.Fuld.], a. 881; Réginon, Chronicon (MGH SS rer. Germ. 50), a. 883 ; pour la date: Annales S. Benigni Divionensis (MGH SS 5), a. 881. 
Dans le "Chant de Louis", les Vikings sont pourtant décrits tout simplement comme païens (heidine man, v. 11), sans que soient évoqués leurs éventuels forfaits. Cependant, des relations comme celles des Annales de Saint-Bertin (à Saint-Omer) témoignent bien d'une présence viking, matérielle autant que psychologique. Sur 53 entrées annuelles, en effet, 30 mentionnent des incursions, des négociations ou des mesures défensives. Je citerai deux extraits, et d'abord les Annales de Saint-Bertin pour l'année 842, sous la plume de Prudence de Troyes:

"Vers ce temps [le mois d'octobre] apparurent soudain, avec le premier jour, à l'emporium de Quentovic des navires des Nordmanni dévastateurs et ils capturèrent et abattirent tout, sans égard pour le sexe, de sorte que rien ne resta que les simples demeures, qui durent encore être rachetées ${ }^{31}$.

Puis un peu plus proche du Rithmus, je mentionnerai les Annales de Saint-Vaast pour l'année 884 :

"Les Nortmanni ne cessèrent de capturer et de tuer le peuple chrétien, de ravager les églises, de détruire les murailles et d'incendier les villages. Toutes les rues étaient jonchées de cadavres de clercs, de laïcs nobles et autres, de femmes, d'adolescents et de nourrissons ${ }^{32}$.

La perception des Northmanni dans les sources du IX ${ }^{\mathrm{e}}$ et $\mathrm{X}^{\mathrm{e}}$ siècles et leur interprétation constitue une tradition historiographique au $\mathrm{XX}^{\mathrm{e}}$ siècle. Après Walther Vogel ${ }^{33}$, et Ferdinand Lot $^{34}$, en passant par Marc Bloch ${ }^{35}$, Lucien Musset ${ }^{36}$ présenta une synthèse équilibrée, comportant une critique de la perspective traditionnelle du phénomène viking. À la même époque, Albert D'Haenens ${ }^{37}$ et Peter Sawyer ${ }^{38}$ sont allés plus loin en mettant en doute l'importance des dégâts causés par les Vikings. Ils ont également soutenu que ceux-ci n'étaient pas les seuls responsables des problèmes économiques que connaît incontestablement l'Occident chrétien vers la fin du IX ${ }^{\mathfrak{c}}$ et le début $\mathrm{du} \mathrm{X}^{\mathrm{c}}$ siècle. On a souligné en même temps l'aspect commercial du mouvement d'invasion. Les Vikings auraient surtout été des negotiatores, assu-

31 Ea tempestate Nordmannorum classis in emporio quod Quantouicus dicitur repentino sub lucem aduentu depraedationibus, captiuitate et nece sexus utriusque hominum adeo debachati sunt ut nihil in eo praeter aedificia precio redempta relinquerent (op. cit., p. 42).

32 Nortmanni vero non cessant captivari atque interfici populum Christianum atque aecclesias subrui, destructis moeniis et villis igne crematis. Per omnes enim plateas iacebant cadavera clericorum laicorum nobilium atque aliorum, mulierum, iuvenum et lactentium (op. cit., p. 54).

33 Walther VogFI, Die Normannen und das fränkische Reich bis zur Gründung der Normandie (799-911), Heidelberg 1906.

34 Ferdinand Lor, Les invasions barbares et le peuplement de l'Europe, Paris, 1937.

35 Marc BI.OCH, La société féodale, Paris, 1939 (première partie).

36 Lucien Musset, Les peuples scandinaves au Moyen Age, Paris, 1951 ; id., second assaut ; id., Nordica et Nordmannica, Paris, 1997.

37 Albert D'HAENENS, Les invasions normandes en Belgique au IX siècle. Le phénomène et sa répercussion dans l'historiographie médiévale, Louvain, 1967

38 Philipp H. SAWYer, The Age of the Vikings, Londres, 1962; plus modéré 20 ans après: Kings and Vikings. Scandinavia and Europe AD 700-1100, Londres/New York, 1982. 
rant les échanges entre le monde scandinave et l'empire franc ${ }^{39}$. Les années quatre-vingt ont apporté une sorte de reflux. On insiste à nouveau sur l'importance des dommages causés par les Vikings. Citons, par exemple, Patrick Wormald ${ }^{40}$ et R. Allen Brown ${ }^{41}$.

Il faut certainement tenir compte de la présence normale de Scandinaves dans les emporia comme Dorestad ou Quentovic, et aussi aux assemblées royales ${ }^{42}$. Il y a aussi plusieurs exemples de Nortmanni recevant des terres en fief ${ }^{43}$. La cession de terres était un modèle critiqué, mais efficace, pour rétablir un ordre quelconque dans les régions sensibles aux raids vikings. Charles le Chauve avait donné au roi breton Salomon une partie de l'Anjou et le Cotentin, qu'il devait protéger contre toute invasion scandinave ${ }^{44}$. Au Xe siècle encore, on voit des chefs vikings se faire baptiser et obtenir des fiefs de Charles le Simple. A l'exception de la future Normandie cependant, ce procédé perdurait rarement au-delà d'une génération, comme le montre l'exemple du pays nantais $(919-937)^{45}$. Tout ceci prouve qu'il existait une communication politique entre Francs et Vikings.

Bien entendu, cela ne veut pas dire que toutes les sources exagèrent. Les invasions, quelque mode qu'elles aient pris, ont sans aucun doute été ressentics comme catastrophiques dans l'empire carolingien. Cela veut plutôt dire qu'il convient de réviser le point de vue traditionnel. Bien sûr, Quentovic et Dorestad furent détruits par les Vikings comme tant d'autres endroits, et la ruine de bien des institutions monastiques à la fïn du IX ${ }^{\mathfrak{c}}$ siècle est évi-

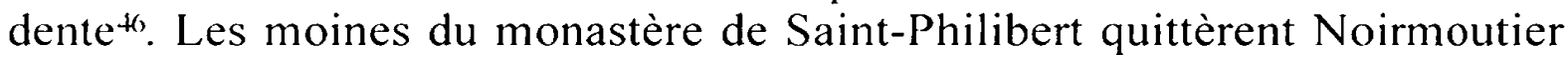
et se déplacèrent à plusieurs reprises, ce dont témoignent les nombreux actes de confirmation de leurs possessions ${ }^{47}$. Nous connaissons maints exemples de communautés religieuses s'enfuyant avec leurs reliques dans d’autres monastères ${ }^{48}$.

Le caractère fatal de ces événements, qui semblaient imparables, trouvait son explication et sa justification, d'un point de vue ecclésiastique, dans

39 Régis BOYIR, Les Vikings. Histoire et civilisation, Paris, 1992, p. 137-139 et passim.

40 (. Patrick WORMAl.D, "Viking Studies: whence and whither?", in : R. Th. FARRIII. (dir.), The Vikings, Londres/Chichester, 1982, p. 128-153.

41 Roger Allen Brown, The Normans, Woodbridge, 1984.

42 Après 830 : Annales Fuldenses a. 845, 848 ; Ann.Bert. a. 831, 836, d'autres négociations paisibles a. $845,862,869$.

43 Annales regni Francorm (MGH SS rer. Germ. 6), a. 826 (Heriold/larald recoit Rüstringen) ; Ann.Bert. a. 841 (Heriold reçoit Walcheren), a. 850 (Rurik reçoit Dorestad) ; Ann.Fuld. a. 882 (Godfrid reçoit le Kennemerland). D'autres exemples: Musset, second assaut, p. 129-132.

44 Ann.Bert. a. 863, 867. Cf. Musset, second assaut, p. 166.

45 I ucien Mussı:T, "Naissance de la Normandie (Ve-XIe siècles) », in : M. ID: BÖ̈ARI) (dir.), Histoire de la Normandie, Toulouse, 1970, p. 75-130 (p. 95-96).

46 MusseT, second assaut, p. 219-222.

47 Monuments de l'histoire des abbayes [!] de Saint-Philibert, éd. R. PoupARI)IN (Collection de textes...), Paris, 1905, p. 110-119.

48 I'HAINENS, invasions normandes, p. 126-129. 
l'image de la punition divine par des hommes cruels. Ceux-ci paraissaient hors norme, et par le fait même invincibles. Cette rhétorique est employée par les annalistes de façon « inflationniste ». Dans la Chronique de Saint-Bénigne, par exemple, l'assaut des étrangers, sarrasins, scandinaves, puis hongrois, est interprété comme une nouvelle translatio imperii du régime franc vers ces extraneos ${ }^{49}$. Rétrospectivement, on observe en effet un déclin du commerce et de la production littéraire au cours du IXe siècle, mais ce ne fut pas la conséquence des raids vikings, comme a pu le montrer Richard Hodges pour les emporia $a^{50}$. Dès les années 820 , il constate un " fall-off in commercial activity » et, à partir de 840 environ, une récession qui se manifeste pour l'archéologue par l'absence totale de traces d'un commerce international.

Les invasions vikings ont ainsi infligé à la population franque un «choc mental qui, lui, était réel ${ }^{51}$. En revanche, elles n'étaient pas à l'origine de la récession économique et de la crise culturelle que l'on observe vers 900 dans l'empire franc, au-delà des rapports des annalistes et des chroniqueurs. Les Francs eux-mêmes ont été, comme Timothy Reuter l'a dit, les Vikings du reste de l'Europe ${ }^{52}$. Bretons, Francs, Moraves ou Vikings partageaient une morale politique commune : c'était une morale barbare au sens propre du terme, qui se distinguait des règles politiques en vigueur dans l'empire byzantin. On pouvait combattre les Vikings, et les battre comme tout autre ennemi. Les victoires franques ne sont pas si rares: Brissarthe, qui se termina avec la mort de Robert le Fort en 866 , et Saucourt en 881 ne sont que les plus fameuses ${ }^{53}$. Ce ne sont pas les actes ravageurs des Vikings qui ont nui à la société franque et à scs structurcs. Ce sont plutôt les problèmes internes de cette société qui ont permis le succès croissant des hommes du Nord.

Cette explication du phénomène viking est renforcée par l'examen du modèle anthropologique de la noblesse du haut Moyen Age. La deuxième moitié du $\mathrm{IX}^{\mathrm{e}}$ siècle est marquée par une émancipation des grands vis-à-vis du système de contrôle mis en place par Charlemagne, qui avait pourtant

49 Chronique de l'abbaye de Saint-Bénigne de Dijon, éd. E. Bougnud et J. Garnier, Dijon 1875 , p. 114.

50 Richard HODgies, «Trade and Market Origins in the Ninth Century : Relations between England and the Continent », in : M. T. GIBSON, J. L. NEISON(dir.), Charles the Bald, Aldershot 1990, p. 203-223, ici 214-217. Voir aussi Stéphane Ll:BE:CQ, «Quentovic : un état de la question ", in : H.-J. HÄSSLER, Cl. L.ORREN (dir.), Studien zur Sachsenforschung 8 (1993), p. 73-82.

51 D'HAFNFN, invasions normandes, p. 72.

52 Timothy RFUTER, «Plunder and tribute in the Carolingian Fmpire», in : Transactions of the Royal Historical Society 35 (1985) p. 75-94.

53 Brissarthe (Ann.Bert. a. 866, Réginon, Chronicon a. 867); siège d'Angers et combat en Francie occidentale (Annales Fuldenses a. 873) ; Thiméon/'Forêt charbonnière' (Annales Fuldenses a. 880, Réginon, Chronicon a. 879). 
fonctionné effectivement ${ }^{54}$. La structure sociale de la société aristocratique se hiérarchise de plus en plus. Le terrain sur lequel peut se développer cette autonomie est celui d'un pouvoir royal diminuant au cours du IX ${ }^{\mathrm{e}}$ siècle. La militia du $\mathrm{X}^{\mathrm{e}}$ siècle, qui sera un des résultats de ce processus de diversification sociale, a seulement commencé à se constituer. Les Vikings trouvaient donc un empire franc sensible aux influences extérieures, s'il ne leur était pas favorable. Ce constat a déjà été formulé dans le Chronicon Namnetense, dont la traduction publiée par René Merlet nous présente « iceux Normans ... contre lesquels ne sesleva nul roy, nul duc, ne nul deffenseur qui les déboutast. Car les rois de France estoient du tout annullez, et n'avoient en eux nulle vigueur de deffense $»^{55}$.

Une autre question problématique est celle des estimations numériques. Là aussi, il faut modérer les donnés des annalistes, qui rapportent des chiffres invraisemblables. D'après nos connaissances, il est peu probable que ces groupes aient compté plus de quelques centaines de combattants. ${ }^{56}$. Cela change après la victoire franque à Brissarthe, qui aurait poussé les Vikings vers de nouveaux objectifs situés en Angleterre. Pour la première fois nous sommes informés d'un mouvement important, qui aurait compris entre 100 et 350 bateaux : il s'agit du fameux magnus exercitus qui retourna vers la côte flamande au cours de l'été 879 . D'après Ferdinand Lot, «les armées normandes comprennent tout au plus de 4000 à 6000 combattants ». Des auteurs plus récents tombent d'accord pour reconnaître que tous les calculs antérieurs doivent être relativisés ${ }^{57}$. En comptant un maximum de 30 hommes par bateau, on arrive à un total de 3000 à 10000 personnes, qui auraient quitté l'Angleterre en 879 . Les estimations de F. Lot se révèlent donc relativement réalistes.

Il est donc problématique de parler, à propos de la bataille de Saucourt, d'une "victoire brillante » qui donna une leçon aux Vikings ${ }^{58}$. Il est beaucoup plus probable que Louis réussit à couper la retraite à une troupe viking rentrant d'un raid. Ce fut sans doute un succès et cela dérangea les Vikings, surtout parce qu'ils étaient privés de leur butin. Aussi la défaite a-t-elle probablement contribué à ce que, par la suite, ils se dirigent plutôt vers la Lotharingie. Mais c'était loin de constituer une victoire décisive ou même une bataille aux résultats durables. Bien évidemment, dans les sources, on trouve

54 LI: JAN, Famille et pouvoir ; ead., "La noblesse aux IXe et Xe siècles : continuité et changements ", in : ead., Femmes, pouvoir et société dans le haut Moyen Age, Paris 2001, p. 190-203; ead., «Réseaux de parenté, memoria et fídélité autour de l'an 800 », ibid. p. 108 118. p. 81 .

55 La Chronique de Nantes, éd. R. Merlet (Collection de textes...), Paris 1896, c. 27,

56 SAWYER, Kings and Vikings, p. 93-94 ; D'HAENENS, invasions normandes, p. 68-72.

57 LOT, invasions barbares, p. 135 ; Carroll GILLMOR, "War on the Rivers: Viking Numbers and Mobility on the Seine and Loire, 841-886», in : Viator 19 (1988), p. 79-109; WORMAI.D, Viking Studies.

58 HARVEY, Provenance p. 5 ; Raimund KEMPER, « Das Ludwigslied und die liturgischen Rechtstitel des westfränkischen Königtums », in : Neue Arbeiten (n. 25), p. 1-17. 
de telles présentations, et il ne faut pas négliger l'effet encourageant produit sur les contemporains. À la fin du XIe siècle encore, Hariulf de SaintRiquier rédige une sorte de memoria de l'événement de Saucourt ${ }^{59}$. À titre de comparaison, mentionnons seulement la victoire de Charles Martel en 732, près de Poitiers, et la défaite de Charlemagne à Roncevaux (778), exaltée dans la Chanson de Roland. Ces deux combats furent tous les deux embellis par la propagande. Par rapport à ces exemples, le Rithmus teutonicus est remarquablement modeste. Le chant fête le roi en mettant l'accent sur ses vertus guerrières (v. 50-54), qui le montrent digne de son ascendance carolingienne, sans qualifier l'importance de la victoire ou caractériser les ennemis. Ceux-ci sont décrits comme païens : leur seule fonction dans le chant est d'apparaître comme les instruments de la punition divine. Et cet attribut de « païen » n'est jugé ni bon ni mauvais.

Pour mieux situer le «Chant de Louis» dans son contexte historique il convient de résumer rapidement l'état de nos connaissances sur les activités vikings au IX ${ }^{\mathrm{e}}$ siècle $^{60}$. Le phénomène normand prit son origine avec l'arrivée de petits groupes de Danois et Norvégiens qui vinrent autant en negociatores tant qu'en praedatores, commerçants et pirates. De nos jours, un tombeau situé sur l'île de Lindisfarne nous renseigne sur le pillage de ce fameux monastère en $793^{61}$. Les premières incursions des Northmanni sont signalées dès 787 en Angleterre, dans une chronique en langue anglosaxonne.

À l'époque du roi Beorhtric arrivèrent pour la première fois trois nefs ; et le prévôt s'y rendit et essaya de les obliger à aller au palais royal car il ne sut ce qu'ils étaient, et ils l'assommèrent ${ }^{62}$.

En 799 , les Vikings paraissent avoir découvert le continent. Entre 820 et 879 , il est question dans les sources de raids nombreux, d'abord sur la côte flamande, puis en Frise et en Aquitaine. Ils commencent à remonter les fleuves, notamment l'Escaut, la Seine et la Loire, ainsi que la Weser et l'Elbe, plus à l'est. En 841 les Vikings sont à Rouen, en 843 à Nantes, en 845 à Hambourg et Paris, et en 848 à Bordeaux. «Les bandes grossissent avec une rapidité de boule de neige : il y a de l'or à gagner $»^{63}$. C'est en 843 pour la première fois qu'ils prennent possession de toute une île pour y hiverner : ils

59 Hariulf, Chronique de l'abbaye de Saint-Riquier, éd. F. Lot, Paris 1894, 1. 3, c. 20, p. 143 : Praedictus ergo Hludogvicus rex in pago Vimmaco cum eisdem gentibus bellum gerens, triumphum adeptus est interfecto eorum rege Guaramundo. Et caesis millibus populi infidelis, caeteri fugati sunt.

60 D'HAENENS, invasions normandes, p. 43-59; MUSSET, second assaut, p. 107-133; SAWYER, Kings and Vikings, p. 86-93; voir aussi John HAYWU()U, Atlas des Vikings, Paris, 1996 , p. 55, 57, 61, 65. Toujours utile : VoGEL, Normannen. p. 17.

61 The Anglo-Saxon Chronicle, éd. D. Dumvil.te et S. KeYNes, t. 6, Cambridge, 1996,

62 Ibid., t. 3, 1986, p. 39.

63 MuSSET, Naissance, p. 93. Cf. l'inscription runique sur la pierre de Gripsholm : SAWYER, Kings and Vikings, tab. IVa. 
érigent un camp à Noirmoutier, non loin de l'estuaire de la Loire. La base suivante sera l'île d'Oissel sur la Seine, en 851 . L'année 858 voit les Vikings entrer à Brême avant qu'ils ne pénètrent, dès le début des années 860 , dans la vallée du Rhin qui passait jusque là pour être sûre. À cette époque, la résistance semble s'être intensifiée : dans les Annales, on parle de ponts et de barrages fortifiés dans la Francia occidentale, qui a toujours été le principal théâtre d'opération des Vikings ${ }^{64}$. "The fortified bridges of Charles the Bald represent a turning point in the history of medieval bridges and fortifications ", écrit Carroll Gillmor ${ }^{65}$. On a souvent jugé inutiles les mesures de défense prises par Charles le Chauve ${ }^{66}$, mais il semble que les barrages sur la Seine ont pu freiner le mouvement. Ainsi, en 876, les Vikings ne purent atteindre Paris et, en 885 , ils durent s'y prendre à plusieurs reprises, ce qui permit aux Parisiens de se préparer.

Si on peut constater dès 866 environ une concentration des campagnes vikings sur l'Angleterre, là aussi la résistance commença à se former. Á la fin du printemps 879 se rassembla une "grande armée » de Vikings dans la Tamise, peut-être avec l'appui de forces nouvelles venant de Scandinavie : elle débarqua vers la mi-juillet entre Calais et Boulogne. C'est là que commença la pire période des invasions vikings sur le continent, suivant les sources, comme par exemple les Annales de Saint-Vaast (à l'année 879) :

"Pendant les querelles sur la succession de Louis le Bègue, les Nortmanni de l'autre côté de la Manche, ayant conscience de la discorde, vinrent sur la mer dans leurs bateaux en multitude infinie et dévastèrent la ville de Thérouanne par le feu et par l'épée, sans que personne ne puisse leur résister $"{ }^{67}$.

Ils remontèrent l'Escaut jusqu'à Gand pour prendre leurs quartiers d'hiver au monastère de Saint-Bavon. Les années suivantes sont caractérisées par de longues expéditions lointaines depuis d'autres camps, dans les anciennes terres centrales de l'empire carolingien. Le Brabant et la Flandre jusqu'à Thérouanne et Saint-Bertin n'étaient qu'un début. Suivirent Tournai et les monastères de la vallée de l'Escaut, entre autres Saint-Amand, puis d'autres objectifs dans les diocèses de Reims et de Noyon, et plus tard dans les vallées de la Meuse et du Rhin. Jusqu'en 892, les sources témoignent, dans ces régions, de raids scandinaves qui ne se limitaient plus à des cibles situées sur les rives des fleuves. Revenant d'une rencontre avec Louis III à Ribemont en 880 , Louis le Jeune, roi de Francia orientalis, réussit à

64 Ann.Bert. a. 862, p. 91.

65 Caroll GILLMOR, "The logistics of fortified bridge building in the Seine under Charles the Bald ", in : Anglo-Norman Studies 11 (1988), p. 87-106, p. 88. Cf. Brian DEARIIIN, " ('harles the Bald's fortified brigde at Pitres (Seine)", ibid. p. 107-112.

66 MUSSET, second assaut, p. 163, 218-219.

67 Nortmanni ultra mare positi, eorum audientes discordiam, navali evectione cum infinita multitudine mare transito Taruennam urbem Morinorum mediante mense Iulio igne et gladio vastaverunt, nemine sibi resistente (op. cit., p. 44). 
surprendre et à vaincre une troupe scandinave. C'était un succès modeste, mais qui fut ressenti comme un signe d'espoir dans le royaume oriental.

À partir d'un nouveau camp, à Courtrai, les Vikings se rendirent à Amiens, Corbie, Arras, et passèrent probablement en chemin par Beauvais, lors d'une campagne qui eut lieu au cours de l'été 881 . Ils rencontrèrent enfin, le 3 août, Louis III à Saucourt. L'annaliste de Saint-Vaast nous renseigne en détail sur cette «bataille » (à l'année 881) :

"Le roi Louis, fort attristé de la détresse de son royaume, convoqua une armée el se prépara au combat. Mais les Nortmanni toujours chanceux traversèrent le fleuve de la Somme au mois de juillet avec une armée importante et ravagèrent tout le pays jusqu'à Beauvais selon leur habitude. Le roi Louis cependant traversa l'Oise avec son armée et se tint vers Lavier où il attendit que les Nortmanni passent à leur retour. C'est pourquoi il envoya épier des guetteurs qui rapportèrent que les Nortmanni seraient sur leur chemin du retour, lourdement chargés de butin. Alors le roi se mit en route contre eux et les rencontra dans la région du Vimeu, près de la villa de Saucourt, et la bataille commença. Bientôt les Nortmanni s'enfuirent vers ladite villa, où le roi les poursuivit, et il triompha d'eux de la façon la plus glorieuse. Et lorsque la victoire fut déjà en partie remportée, les guerriers commencèrent à se vanter de ce qu'ils auraient achevé de leur propre force et ne rendirent pas gloire à Dieu. Et puis quelques Nortmanni s'évadèrent de ladite villa, mirent en fuite toute l'armée et tuèrent un bon nombre d'hommes, presque une centaine. Et si le roi, en descendant rapidement de cheval, ne les avait pas arrêtés et ne leur avait pas donné de l'audace, ils auraient tous quitté cet endroit par une fuite honteuse. Après que cette victoire ait été véritablement remportéé, et triomphant à cause de la mort de tant de Nortmanni, le roi rentra sur l'Oise; très peu de Danois évadés racontèrent au camp la défaite des leurs : et à partir de ce temps-là, les Nortmanni commencèrent à redouter le jeune roi ${ }^{68}$.

En réalité, Les Vikings ne craignirent pas suffisamment Louis III pour renoncer à d'autres raids, qui les menèrent à Maastricht, Liège et Tongres. La grande campagne en Rhénanie était encore à venir. Réginon de Prüm

68 Interim Hiudowicus rex gravi dolore contristatus, videns regnum deleri, convocato exercitu praeparat se ad proelium. At Nortmanni omnia prospera agentes cum magno exercitu fluvium Sumnam mense Iulio transeunt, cuncta vastantes more solito usque prope civitatem Belvagorum. Hludowicus vero rex cum exercitu transiens Hisam fluvium Latverum tendere coepit. quo credebat Nortmannos redire. Missis itaque exploratoribus, nuntiant redire eos honustos a praeda. Contra quos rex ire perrexit obviavitque eos in pago Witmau, in villa quae dicebatur Sathulcurtis, et commissum est proelium. Moxque Nortmanni fügam ineunt atque dictam villam deveniunt; quos rex insecutus est gloriosissimeque de eis triumphavit. Et patrata victoria ex parte coeperunt gloriari suis hoc actum viribus et non dederunt gloriam Deo. Paucique Nortmanni ex dicta villa egressi, omnem exercitum vertit in fugam, pluresque ex eis, videlicet usque ad centum homines, interfecerunt : et nisi rex citius equo descendens locum resistendi et audaciam suis donaret, omnes turpiter ex eodem loco fugiendo abirent. Hac vero patrata victoria. quia multos contigit ibi ruere Nortmannos, rex ovans repedavit trans Hisam, perpauci vero Dani, qui evasere, interitum suorum nuntiavere in castra, indeque Nortmanni IIludowicum regem adolescentem timere coeperunt (op. cit., p. 50-51). 
nous raconte par le menu l'expédition des deux reges Nortmannorum qui auraient pillé Cologne, Bonn, Zülpich (Tolbiac), Jülich et Neuss, puis Aixla-Chapelle avec plusieurs monastères, dont Prüm, et finalement même Trèves. D'un autre côté, l'un de ces rois vikings, Godfrid, reçut d'un roi franc un fief et une épouse de la famille carolingienne. Charles le Gros lui donna en effet le Kennemerland frison en 882. C'est probablement lui aussi qui arrangea son mariage avec Gisèle (Gisla), fille de Lothaire II et de Waldrade, et donc lointaine cousine de Louis III. Godfrid fut assassiné en 885 . On tirera deux conclusions de cet épisode. Un rex Danorum pouvait être accepté comme partenaire en matière politique, mais on mettait fin à l'alliance si le fidelis ne se révélait pas fiable. Ce fut le cas de Godfrid, qui laissait passer des bateaux vikings sur le Rhin ${ }^{69}$.

La fin de l'histoire, au moins pour le nord du royaume occidental, l'ancienne Neustrie, est le célèbre traité de Saint-Clair-sur-Epte. La ville de Rouen et ses alentours furent donnés en fief par Charles le Simple à un autre roi viking, d'origine norvégienne, cette fois-ci, nommé Hrólfr ou bien Rollon en langue romane. C'est à partir de 911 qu'on parle d'un comte (de Rouen), et plus tard d'un duc de Normandie ${ }^{70}$.

Sur la base de ces connaissances révisées sur les Vikings et sur la façon dont ils étaient perçus par les gens du $I^{\mathrm{e}}$ siècle, il est maintenant possible d'entreprendre une analyse plus précise du texte du Rithmus teutonicus.

«D'illustres ancêtres, une famille noble, des parents et des amis, la reconnaissance et la liberté sociales, voilà ce qui faisait un noble, au VII ${ }^{e}$ comme au $\mathrm{X}^{\mathrm{e}}$ siècle ». Cette définition a été formulée par Régine Le $\mathrm{Jan}^{71}$, et le public du $I^{\mathrm{e}}$ siècle aurait pu la retrouver dans le "Chant de Louis". Après les informations de base, sur le plan biographique, les premiers vers du Rithmus caractérisent le roi Louis : il est humble envers Dieu, qui l'a adopté à la place de son père décédé, et c'est grâce à cette haute protection qu'il possède les vertus convenant à un souverain. Pour Louis, Dieu luimême fut le Magaczogo, le précepteur, comme le montre le poème (v. 3-4).

"Kind wuarth her faterlos. Thes uuarth imo sar buoz.

Holoda inan truhtin. Magaczogo uuarth her sin".

"Jeune, il perdit son père, bientôt il en fut récompensé.

Le Seigneur se chargea de son destin, il devint son précepteur ».

69 Je me réfère à l'intervention d'Alain DIERKENS sur "Les Vikings en Lotharingie » lors du colloque Les fondations scandinaves en Occident et les débuts du duché de Normandie (25-29 septembre 2002) qui fut organisé à Cerisy-la-Salle par Pierre BAuduun et Claude LORREN.

70 Actes de Charles III, $\mathrm{n}^{\circ}$ 92, p. 209-212: Compiègne 14 mars 918. MussET, second assaut, p. 253-261; id., "Ce que l'on peut savoir du traité de Saint-Clair-sur-Epte ", in : id., Nordica et Nordmannica, Paris 1997, p. 377-381 ; François NEveuX, La Normandie des ducs aux rois. $X^{\prime \prime}-X I I^{\prime}$ siècle, Rennes 1998, p. 17-42 ; Renaud, Vikings, p. 56-64. Sur Rollon : ibid., p. 47-55; MUSSET, Naissance, p. 97.

71 L.: JAN, noblesse, p. 190. 
Dieu remplaçant le père, le roi dispose de toutes les nobles qualités nécessaires : il porte un nom de valeur symbolique - Louis est justement la forme moderne de Clovis -, et partage généreusement le trône avec son frère. L'auteur du chant prend soin de le présenter dès le début comme capable d'accomplir le ministère royal. Il va sans dire que cela implique la liberté sociale de la définition citée, tandis que la reconnaissance dans la société doit être acquise, ce qui est justement le sujet du poème.

En dehors de cette perspective anthropologique, on retrouve dans le Rithmus le type idéal du souverain chrétien, ce qui autorise à parler d'un panégyrique. Louis est décrit comme humble selon l'image du rex et servus Dei. Dès le début, le public sait qu'il obéit à Dieu et qu'il sera sans doute récompensé. Il reçoit une mission par un dialogue sans intermédiaire avec Dieu et, par la suite, fait tout pour l'accomplir : il rentre aussitôt dans son pays, rassemble une armée, l'encourage par un discours (v. 32-41) et s'engage personnellement au combat.

"Trostet hiu giselleon. Mine notstallon.

Hera santa mih god. Ioh mir selbo gibod. Ob hiu rat thuhti. Thaz ih hier geuuhti. Mih selbon ni sparoti. Unc ih hiu gineriti.

$\mathrm{Nu}$ uuill ih thaz mir uolgon. Alle godes holdon. Giskerit ist thiu hieruuist. So lango so uuili krist.

Uuili her unsa hinauarth. Thero habet her giuualt.

So uuer so hier in ellian. Giduot godes uuillion.

Quimit he gisund uz. Ih gilonon imoz.

Bilibit her thar inne. Sinemo kunnie".

"Soyez consolés, mes compagnons!

Dieu m'envoya ici et lui-même m'ordonna,

$s$ 'il vous semble bon qu'ici je combatte,

et que je ne m'épargne pas jusqu'à ce que je vous aie libéré.

Maintenant je veux que me suivent tous les fidèles de Dieu.

L'ici-bas est délimité autant qu'il plaise au Christ,

$S$ 'il veut notre trépas, cela est en son pouvoir.

Qui accomplit ici avec zèle la volonté de Dieu,

s'il survit, je vais l'en récompenser,

S'il tombe au combat, [je récompenserai] sa famille ».

Grâce à Dieu et aux saints il remporte la victoire (sin uuarth der sigikamf, v. 56). Ce thème constitue l'épreuve du jeune roi. Mais on rencontre dans le poème un deuxième thème, qui est de la même façon imprégné de représentations bibliques. C'est le motif du peuple en détresse qui attend un sauveur. Ce salvator sera Louis III, qui est envoyé par Dieu directement chez les Francs, identifiés avec le peuple élu (v. 23-24).

"Hluduig kuning min. Hilph minan liutin.

Heigun sa northman. Harto biduuungan".

"Louis, mon roi, aide mes hommes!

Les Vikings les ont fort étreints." 
Par comparaison, voici la scène de la vocation de Moïse (Exode 3, 9-10) :

Clamor ergo filiorum Israhel venit ad me

vidique adflictionem eorum qua ab Aegyptiis opprimuntur

sed veni mittam te ad Pharaonem

ut educas populum meum filios Israhel de Aegypto.
"Le cri des Israëlites est venu jusqu'à moi, et j'ai vu l'oppression que font peser sur eux les Egyptiens.
Maintenant va, je t'envoie auprès de Pharaon, fais sortir d'Egypte mon peuple, les Israëlites'».

En opprimant les Francs, les Vikings sont les Égyptiens du poème, et l'auteur nous fournit une explication. Dans le "Chant de Louis », la fonction des Northmanni est d'exhorter et de punir les Francs (v. 11-12), qui ne vivaient plus en bons chrétiens. Ce fut un succès, comme nous le constatons, car le châtiment les obligea à se corriger (cf. l'énigmatique Haranskara, v. 14). Dans le cadre de ce thème, Louis est mis en relation avec des modèles bibliques, technique répandue pour louer ou critiquer un souverain. Le roi est ainsi une figure de Moïse et aussi du Christ lui-même, car c'est également une imitatio Christi qui est décrite. Louis est le sauveur attendu depuis si longtemps (So lango beidon uuir thin, v. 30). C'est donc aussi un modèle idéologique qui est peint, si l'on peut dire, en parfait accord avec une conception laïque de la royauté. Sur la base de l'idée gélasienne des deux pouvoirs, spirituel et temporel ${ }^{72}$, le Rithmus défend une interprétation équilibrée: les représentants des deux pouvoirs se trouvent au même niveau. À la suite de l'onction reçue lors de son sacre, en effet, le roi n'est pas subordonné au pouvoir épiscopal. On trouve donc une illustration de la pensée cléricale dans le Rithmus teutonicus : celui-ci est construit sur deux épreuves, celle du peuple franc et celle de Louis III, qui sont remportées par le roi chrétien idéal.

Ce résultat ne peut étonner, étant donné que tous les textes de cette époque ont été rédigés soit dans un monastère ou un évêché, soit dans l'entourage du roi, et donc par des auteurs de formation cléricale. Mais il prouve toutefois que le « Chant de Louis » a vraiment été composé après Saucourt, et non pas sur la base d'un quelconque poème antérieur. Aussi voit-on qu'il ne s'agit pas de propagande anticléricale. Il est possible cependant que la façon de présenter le roi et son rapport privilégié avec Dieu (Hera santa mih god. Ioh mir selbo gebod, v. 33) doive être mis en relation, consciente ou pas, avec le conflit entre le roi et le métropolitain Hincmar, à propos de l'investiture de l'évêché de Beauvais ${ }^{73}$.

72 Concilium Parisiacense de 829 (MGH Conc. 2.2). Cf. Jean Dl:vissi, Hincmar. Archevéque de Reims 845-882, Genève 1976, p. 671-723.

73 Di:vissi, Hincmar, p. 979-990; Gerhard ScHMIT\%, " Hinkmar von Reims, die Synode von Fismes und der Streit um das Bistum Beauvais ", in :Deutsches Archiv 35 (1979), p. 463 486 ; MATTHIIIR, Historisches und Figuratives ; YEANIDL, Ludwigslied. 
On a aussi constaté des allusions au changement de la condition noble au $\mathrm{IX}^{\mathrm{e}}$ siècle $^{74}$. Bien sûr le roi suit le principe du consensus fidelium. Les actions menées par le roi, d'abord militaires puis administratives, doivent être conduites avec l'accord des grands de son royaume. Or, le roi du Rith$m u s$ ne convoque pas l'assemblée de ses fidèles seulement pour s'assurer de leur consentement, pour légitimer ce qu'il a décidé, ou bien ce que Dieu lui a ordonné (Ob hiu rat thuhti - s'il vous semble bon, v. 34). Il est au contraire conscient de l'importance du consilium : il s'agit là d'une véritable conditio sine qua non. La royauté prend de plus en plus le caractère d'un ministère. «Les grands ne sont plus astreints à l'aide et au conseil en vertu de leur fidélité au roi, de l'impératif de la communis utilitas, ou de l'application du droit, mais en contrepartie de leur participation effective aux décisions royales $" »^{75}$. Cette nouvelle conception, qui trouve un reflet dans le "Chant de Louis ", résulte du pouvoir et de l'influence croissants des grands, mais représente aussi le succès de l'idée cléricale du caractère idoine du souverain, qui doit subir des épreuves.

Un autre indice se trouve dans le discours du jeune roi avant le combat (v. 32-41). Louis III encourage ses fidèles avec deux arguments : l'accomplissement de la volonté de Dieu et la promesse de récompense. C'était probablement chose courante, tant qu'existait la garantie explicite de remettre les biens en question aux familles de ceux qui ne survivraient pas (v. 39-41). Le fait cependant que l'auteur du Rithmus consacre trois vers à une coutume tout à fait normale me semble indiquer qu'il voulait souligner quelque chose de particulier. On l'a interprété comme une confirmation de l'hérédité des fiefs qui aurait été fixé par Charles le Chauve peu de temps avant ${ }^{76}$. Il est vrai que Charles, devenu empereur, réglait beaucoup de choses dans le capitulaire de Quierzy avant sa dernière campagne italienne en $877^{77}$. Or, si on regarde de près les chapitres 9 et 10 , on remarque qu'il s'agit là non pas d'une hérédité automatique des charges, mais que le roi gardait toujours le dernier mot. À cela s'ajoute que ce capitulare Carisiacense n'est plus considéré aujourd'hui comme l'acte de naissance de la transmission des honores du père au fils. Il y a des exemples de la patrimonialisation des charges qui remontent au VIII ${ }^{\mathrm{e}}$ siècle $^{78}$. Ainsi, l'évocation de cet aspect du système des bénéfices dans le «Chant de Louis " reflète une réalité historique. Pourquoi avoir mentionné quelque chose de parfaitement normal ? Peut-être pour communiquer une image rassurante du roi qui acceptait en public ce qui était entré dans les faits, mais pas dans la loi, peut-être pour faire allusion à un grand-père modèle.

74 MatThill:R, Historisches und Figuratives ; KLMPI:R, Ludwigslied im Kontext ; id., Rechtstitel.

75 LE JAN, noblesse, p. 191.

76 KEMPER, Ludwigslicd im Kontext, p. 172-173.

77 MGH LL Capit. II no. 281, p. 355-361.

78 LE JAN, Famille et pouvoir, p. 253-257; ead., Histoire de la France : origines et premier essor. 480-1180, Paris 1996, p. 100. 
Nous tenterons de formuler quelques conclusions. Le Rithmus teutonicus décrit et glorifie la victoire de Louis III sur une troupe de Scandinaves, «à la tête de quelques maigres contingents de l'armée royale ", comme on l'a écrit ${ }^{79}$. Ce fut pourtant un succès célébré, dont témoigne ce chant épique qui a été composé peu après, en tout cas avant la mort du roi, donc entre août 881 et août 882 . Dans le poème se reflètent plusieurs aspects du contexte historique, comme les conditions de la succession au trône de Louis III ou le partage du royaume occidental entre lui et son frère Carloman. Il est remarquable que les Vikings, les antagonistes du roi, ne soient point caractérisés, sinon comme païens. Le seul exemplaire du texte qui nous est parvenu, dans un manuscrit de l'abbaye de Saint-Amand, fut probablement produit pour la bibliothèque de ce monastère, en cours de reconstitution. Saint-Amand faisait partie des cibles des raids vikings du début des années 880 et a perdu à cette occasion la plupart de ses archives. Le manuscrit Valenciennes 150 a donc été composé peu après la mort de Louis III.

Si la copie du Rithmus pourrait être localisée dans un autre monastère, ce n'est pas forcément le cas en ce qui concerne son auteur. Nous ne savons rien, comme d'habitude, de son identité, mais il existe des indices qui permettent d'approcher sa personnalité. Cet auteur connaît bien les modes ecclésiastiques d'interprétation du monde, sans être partisan d'un modèle idéologique; il ne semble pas prendre parti, au moins pas expressis verbis, pour ou contre une position politique. La question du caractère idoine du roi paraît très importante. Elle peut être considérée aussi bien comme une revendication ecclésiastique que comme un élément mythique dit germanique, le «Königsheil », c'est-à-dire le salut provenant de l'ascendance et du bon gouvernement du roi ${ }^{80}$. Il n'est peut-être pas trop osé de constater que l'auteur balance très habilement entre ces deux aspects d'un même topos. Le roi est idoine parce qu'il obéit à Dieu et mène à bien ce qu'il lui ordonne ; l'absence du roi est à l'origine du bouleversement de son royaume, ce qui met Dieu en colère (v. 20). Ses épreuves, en particulier dans le combat (v. 51-54), remettent tout en ordre. En insistant sur la légitimité du règne de Louis III - novus Salomon etc. - et sur son autorité quasi divine, l'auteur en reste à une conception traditionnelle de la royauté, je dirais même nostalgique. Ajoutons que l'auteur se montre familier des conditions de vie des nobles laïcs, si l'on suit l'interprétation du discours avant la bataille que nous avons évoquée, avec la mention des fiefs héréditaires (v. 32-41). Tout cela mène à la conclusion que l'auteur est à chercher plutôt du côté du roi que du côté d'un évêque, et probablement dans son entourage, à sa cour ${ }^{81}$.

79 LE JAN, origines, p. 103.

80 La discussion actuelle sur les termes ( germanique > et ( Germains > montre de plus en plus qu'un groupe de personnes auquel on pourrait attribuer ces termes n'existait pas. II convient de les utiliser en langage technique philologique seulement, où ils signifient un groupe de langues. Voir bientôt les actes du colloque «Zur Geschichte der Gleichung germanisch - deutsch » sous la direction de Heiko STEUER et al.

81 MATthEIER, Historisches und Figuratives; HAUBRIChS, Anfänge, p. 143-144. 
Vu la forme extraordinaire du Rithmus mêlant les longs vers à la rime, la question se pose de savoir si son auteur avait connaissance de l'œuvre du moine de Wissembourg, Otfrid, qui était, d'après nos connaissances, le premier à se servir de ce style, et qui l'a donc peut-être inventé. Lui aussi est l'auteur d'un panégyrique qui prend la forme d'un poème de dédicace de son "Livre des évangiles » à Louis le Germanique, datant des années $860^{82}$ bien qu'il faille constater que la maîtrise métrique du «Chant de Louis » est remarquablement plus développée.

La forme du poème nous donne encore un autre indice, qui reste à interpréter. Le titre de Rithmus semble prouver que le texte ne servait pas à la lecture (seulement), mais à la récitation musicale. Wolfgang Haubrichs a rapproché le "Chant de Louis » des Laudes, éloges chantés lors de l'arrivée et de l'accueil du roi (Adventus regi) ${ }^{83}$. Ainsi peut-on imaginer que les trois ou cinq derniers vers étaient chantés, en pensant aux acclamations décrites par les Annales de Fulda ${ }^{84}$, par exemple, ou par Ekkehard de Saint-Gall ${ }^{85}$ : Heil hero! heil liebo! « Salut au seigneur, salut à l'ami chéri ». Citons à nouveau le Rithmus (v. 57-59):

"Uuolar abur hluduig. Kuning uilo salig.

So garo soser hio uuas. So uuar soses thurft uuas.

Gihalde inan truhtin. Bi sinan ergrehtin".

"Salut toutefois à Louis, au roi si bienheureux!

Si prêt qu'il fut toujours, où jamais fut besoin ;

Le Seigneur le garde en sa bonne grâce ».

Le contcxtc de la transmission du Rithmus dans le manuscrit Valenciennes 150 confirme cette interprétation, car les deux cantilènes de sainte Eulalie, latine et française, comme les deux autres séquences Dominus caeli rex et Vis fidei tanta est, furent très probablement destinées à une interprétation musicale ${ }^{86}$. Cela explique l'intérêt d'un monastère pour ces textes, et aussi l'intérêt de les réunir dans un codex : «Nous savons qu'une des fonctions principales de l'abbaye de Saint-Amand était la fonction d'accueil... Il fallait édifier les hôtes de l'abbaye avec la récitation de textes en sermo vulgaris, tout comme le prescrivit le synode de Tours, les francophones avec un texte en français (Cantilène de sainte Eulalie) et les germanophones avec un texte en francique rhénan ${ }^{87}$.

82 Otfrids Evangelienbuch, éd. O. ERDMANN et L. WOLFF, Tübingen 1973. Cf. SCHNEIDER, Anmerkungen.

83 HAUBRICHS, Anfänge, p. 140-144; id., Georgslied und Georgslegende im frühen Mittelalter, Königstein, 1979, p. 165, 176-177; KLMPER, Ludwigslied im Kontext, p. 168-169.

84 Annales Fuldenses a. 891, p. 121.

85 Ekkehard IV., Casus Sancti Galli, éd. H. F. HAEFEle (FSGA), Darmstadt 1980, c. 19, p. 50 .

86 HFLliARDT, Mehrsprachigkeit, p. 24-27.

87 Dieter WHI.KE, «Forme linguistique et origines du Rithmus teutonicus (Ludwigslied) : remarques sur un énigme », in : Eulalie 1990, p. 89-95, 94. 
Posons, pour terminer, la question de la valeur du chant en tant que source historique. Notre poème fait preuve, comme on a vu, d'une « empreinte cléricale $\aleph^{88}$, qui est tout à fait typique de l'époque. Au centre du récit il n'y a rien d'autre que le protagoniste, le roi " en Francie » (hier in urankon, v. 6), qui sert Dieu et en sera récompensé, ce qui est anticipé au deuxième vers. La fonction d'antagoniste revient aux «hommes païens » (v. 11) qui pourtant, on l'a vu, ne sont là que pour remplir leur fonction de punition. Il en est de même pour les Francs, sur lesquels nous en apprenons un peu plus, mais qui, eux aussi, sont décrits de façon assez schématique. Le poème entier sert à la glorification et, déjà, à la mémoire de Louis III, vainqueur des Vikings. La conclusion est évidente : Dieu est de nouveau avec nous. Le contenu en matière d'information semble maigre, au-delà des événements qui sont décrits de façon plus détaillée dans d'autres sources.

Tout devient plus clair si on se rend compte de l'utilisation des topoi dans le Rithmus. La présentation du roi se lit comme un récit hagiographique. Depuis sa jeunesse, le roi est en relation privilégiée avec Dieu, qui se déclare son père, comme il l'a fait pour le fils et successeur du roi David ( $1^{\text {er }}$ Livre des Chroniques 17, 13). Le roi franc correspond ainsi à Salomon et au Christ même. Louis a des épreuves à passer, il commet des fautes, mais à la fin il s'avère bon roi et Vicarius Dei. L'explication des invasions des Vikings comme punition divine témoigne en premier lieu de l'impuissance des faiseurs d'opinion du roi, mais s'inscrit dans la perspective de l'histoire du Salut. Elle allait devenir un motif répandu dans les sources. Et c'est là le mot clé pour l'analyse de ce chant : la représentation d'une histoire du Salut qui remonte à saint Augustin et à Orose et à leur interprétation du Livre de Daniel $(2,21)$.
Et ipse mutat tempora et aetates
transfert regna atque constituit
dat sapientiam sapientibus et
scientiam intelligentibus disciplinam.
"C'est lui qui fait alterner périodes et temps,
qui fait tomber les rois, qui établit les rois,
qui donne aux sages la sagesse
et la science à ceux qui savent discerner».

La bénédiction de Dieu par le prophète Daniel, après la vision nocturne qui le sauva de la mort, est la référence principale de l'interprétation du cours de l'histoire comme une suite d'épreuves, dirigées par le Dieu toutpuissant, qui mènent finalement au salut universel ${ }^{89}$. Ce n'est pas le détail qui compte, mais la perspective. Ainsi n'est pas mentionné le tournant positif de la bataille de Saucourt, dû à Louis III. Nous n'avons pas non plus

88 Di:liboullil: deux séquences, p. 34.

89 Karl Ferdinand WERNER, "Gott, Herrscher und Historiograph », in : id., Einheit der Geschichte, Sigmaringen 1999, p. 89-119; Bernard GUI:NIE, Histoire et Culture historique dans l'Occident médiéval, Paris 1980, p. 29-31. 
d'autres informations sur les Francs : ils figurent comme un peuple élu qui a quitté le bon chemin, et qui en est nécessairement puni. La victoire sur les Vikings n'est pas le succès des Francs : elle est seulement due à la vertu du roi et, en dernier ressort, à Dieu. Même la réussite de Louis III, hors de la perspective salutaire, serait futile et ses exploits vaniteux.

Qu'est-ce qui en résulte? L'analyse du « Chant de Louis » nous livre des informations concernant l'histoire des mentalités. Sur les mentalités, "une multitude de croyances et de pratiques ${ }^{90}$, nous avons bien peu de témoignages de l'époque du haut Moyen Age. Peut-être le «Chant de Louis» peut-il élargir nos connaissances dans ce domaine.

Sur le plan anthropologique, le texte nous livre des informations sur les rites et pratiques cérémonielles. Il y a un rituel antérieur à la bataille, pour encourager les combattants et, en cas de victoire, l'acclamation de celui qui a mené les troupes au combat. La personne de ce dernier apparaît comme un élément constitutif, surtout s'il s'agit du roi. Le Rithmus témoigne de ce qu'on a appelée «charismatic task »du chef d'armée ${ }^{91}$. L'insistance de l'auteur sur le rôle du roi, et sur les rituels d'avant et d'après (respectivement v. 10,11, et 5), permet de généraliser ces éléments et d'y voir un trait caractéristique de la société noble.

L'autre aspect de la définition citée plus haut concerne les croyances. Pour en savoir plus sur les mentalités du IX ${ }^{\mathfrak{c}}$ siècle, il faut s'interroger sur les systèmes de valeurs ${ }^{92}$. Qu'est-ce que nous apprend le «Chant de Louis »? Première observation : le roi n'est un bon roi que s'il est victorieux au combat, et c'est de la présence royale, au combat et dans d'autres contextes, que dépend le sort du royaume. Les nobles n'y figurent point. Le texte nous renseigne ainsi sur l'imaginaire de la royauté au $I X^{e}$ siècle, qui est caractérisé par la vertu guerrière. La maîtrise des armes est la qualité principale du roi : elle est glorifiée et détermine sa mission sociale ${ }^{93}$. Le devoir et la responsabilité du roi sont décrits ex negativo dans la partie du Rithmus qui sert d'introduction à la bataille : le roi est loin et son peuple souffre. À la fín du texte, Louis accomplira sa fonction protectrice grâce à un succès militaire (v. 46, 50-54).

"Ther kuning reit kuono . sang lioth frono

Thar uaht thegeno gelih. Nichein soso hluduig. Snel indi kuoni. Thaz uuas imo gekunni

$90 \mathrm{Bl} . \mathrm{OCH}$, société féodale, p. 129 sur les mentalités religieuses.

91 Karl LEYSER, "Early Medieval Warfare », in : id., Communications and Power in Medieval Europe, London/Rio Grande 1994, p. 29-50.

92 Cf. Jacques LE GOFF, "Les mentalités. Une histoire ambiguë », in : J. LE GrofF, P. NORA (dir.), Faire de l'histoire, t. 3 : Nouveaux objets, Paris 1986, p. 106-129, ici p. 108.

93 Cf. Hans-Henning KorTüm, Menschen und Mentalitäten. Einführung in die Vorstellungswelten des Mittelalters, Berlin 1996, p. 41-51 ; Régine LE JAN, «Remises d'armes et rituels du pouvoir chez les Francs : continuités et ruptures de l'époque carolingienne », in : Femmes, pouvoir (n. 52), p. 171-189. 
Suman thuruhskluog her. Suman thuruhstah her.

Her skancta cehanton. sinan fianton.

Bitteres lides. So uue hin hio thes libes".

"Téméraire, le roi chevaucha, il chanta un chant sacré

$\dddot{L} \dot{a}$ combattit chacun des guerriers, aucun ne le fit comme Louis : brave et téméraire, ce lui était inné.

Il assomma l'un, tua l'autre à coup d'épée.

il versa aussitôt à ses ennemis

un hreuvage amer; misère toujours à leurs vies».

La description de la bataille est en même temps le moyen de glorifier l'exercice du métier noble par le jeune roi, un art qui est considéré comme une valeur en soi, et qui se manifeste aussi dans le seul loisir qui convient au noble, la chasse $e^{94}$. À cela s'ajoute une tendance idéalisatrice qui s'articule sur l'éloge des Francs. Dans les textes vernaculaires, peu nombreux au IX siècle, on rencontre ce topos, comme dans le poème de dédicace pour Louis le Germanique de Otfrid de Wissembourg ${ }^{95}$. C'est ainsi que fonctionnent les mécanismes d'identité. L'auteur du Chant évoque, en langue francique, une identité franque (hier in urankon, v. 6), qui se réfère très probablement à la totalité de l'empire franc. Il glorifie aussi l'art de combattre des Francs (Spilodun ther urankon, v. 49). A partir de ces éléments, il érige un monument à la mémoire de Louis III, qui va s'ancrer dans la memoria collective.

La deuxième observation est très courte, car il suffit de répéter que le texte nous livre une interprétation des événements suivant le modèle de l'histoire du Salut. Légitimés par la source de la vérité la plus pure ${ }^{\%}$, c'est-à-dire la Bible, les Vikings sont présentés comme instrument de la volonté divine. La menace de la chrétienté par des invasions barbares, " une mentalité médiévale », pourrait-on se demander, en faisant allusion à un article fameux de Georges Duby ${ }^{97}$.

Le Rithmus teutonicus confirme donc ce que nous croyons savoir sur les catégories centrales des représentations collectives: Quelle vision du pouvoir? Quelle conception de la société ${ }^{88}$ ? L'auteur nous présente une perception de la fonction royale qui laisse de côté la noblesse. Le salut du roi, l'absence et la présence du roi, nous l'avons vu, sont des concepts déjà démodés vers cette fin du IX ${ }^{\mathrm{e}}$ siècle. Ils témoignent de l'aspect conservateur de la conception de la royauté qui nous est proposée. Cependant, l'auteur ne

94 Jörg JARNUT, «Die frühmittelalterliche Jagd unter rechts- und sozialgeschichtlichen Aspekten », in : id., Herrschaft und Ethnogenese im Frühmittelalter, Münster 2002, p. 375 418 ; KORTÜM, Menschen, p. 41-51.

95 Voir supra, n. 82.

96 Cf. Homann, Dichtung im Dienste der Politik, p. 27 : "Quelle der reineren Wahrheit ».

97 Georges DuBY, "La Féodalité ? Une mentalité médiévale », in : Annales E.S.C., 13 (1958), p. 765-771. On pensera au titre de l'ouvrage classique de Lucien MUSSET (n. 23).

98 Ll: Gorf, Les mentalités, p. 118, 121. 
peut tout de même pas supprimer la réalité de la participation croissante des nobles au pouvoir.

Le rôle des Northmanni comme exécuteurs de la punition divine fait partie des mentalités médiévales. On est d'autant plus frappé par la présentation tout à fait neutre des Vikings dans le Rithmus, qui ne s'inscrit dans aucun modèle de notre connaissance, ecclésiastique ou autre. Cela permet de considérer, pensons-nous, le «Chant de Louis » comme le témoignage exemplaire d'une vue plus équilibrée concernant les invasions vikings. Finissons donc par une banalité en matière d'historiographie : l'histoire est écrite par les vainqueurs. Pour étudier les Vikings dans la Francie au IX ${ }^{\mathrm{e}}$ siècle, nous disposons de peu d'éléments en dehors des sources franques. Pour elles, le proverbe byzantin cité par Eginhard est toujours significatif : "Que le Franc soit ton ami, et non pas ton voisin $»^{99}$.

\section{Jens SCHNEIDER}

Institut zur Interdisziplinären Erforschung des Mittelalters und seines Nachwirkens. Université de Paderborn

99 Eginhard, Charlemagne, c. 16, p. $50: T$. 